\title{
The Socio-Economic Role of Entrepreneurial Universities in Development of Innovation-Driven Clusters: The Russian Case
}

\author{
Olga N. Korzhenevskaya ${ }^{1}$ \\ ${ }^{1}$ Volgograd State Technical University, Volgograd, the Russian Federation \\ Correspondence: Olga N. Korzhenevskaya, Volgograd State Technical University. 400005, 28, Lenin Avenue, \\ Volgograd, the Russian Federation. Tel: 7-937-712-01-33. E-mail: olga.korzh0309@gmail.com; olga@ikorzh.ru
}

\author{
Received: July 18, 2014 Accepted: August 24, 2014 Online Published: November 14, 2014 \\ doi:10.5539/ass.v10n23p113 URL: http://dx.doi.org/10.5539/ass.v10n23p113
}

\begin{abstract}
Nowadays, Russia has to build its foreign policy in the difficult conditions of aggravation of international relations with the traditional economic partners, imposing sanctions on leading domestic enterprises and restricted access to resources such as capital in world markets. Of course, all these factors have the negative impact on the Russian economy as a whole. So it requires rapid business-process reengineering in the existing economical system and more effective organization of domestic industry. Restriction on actions in accustomed markets, in familiar environment provokes a pre-crisis situation. It creates a strong motivation to inner development of the national economy, commitment to internal business needs and diversification of priorities for long-term cooperation. So, it is very important for Russia to find the effective tools of real socio-economical improvements in home markets and revitalize its business climate. The good alternative to raw-based orientation is advancement of manufacturing industry and high-tech production. Unfortunately, it happens not so often in many brunches of Russian economy. For an isolated case to become a national trend, it is necessary to create an intertwined system of stable relations between enterprises and institutional organizations in different regions of the country. This article analyzes the prospects for creation of regional innovation-driven clusters in specific Russian conditions. The special role in formation of such clusters belongs to entrepreneurial universities, which are not only able to generate new technologies and innovative products, but also serve as a source of institutional, organizational, cultural and communication innovations that are useful for the business community.
\end{abstract}

Keywords: entrepreneurial university, cluster, knowledge-based economy, innovation, economic effect

\section{Introduction}

Today's world economy is characterized by the strong trend of globalization, abrupt acceleration of scientific and technological progress, especially in comparison with previous decades, and significant role and value of knowledge that is the most important economic resource and a source of competitive advantage in business in modern economy. Economic systems of industrialized countries form emerging global trend of world economic development. They demonstrate more and more characteristics and effects that indicate on the new socio-economic order - knowledge-based economy that will change the fundamentals of business, production, communications and competition in the world's largest markets for goods and services in the near future. In the context of the knowledge-based economy competitiveness of a country is determined by its ability to create new knowledge quickly and effectively, including export-oriented technologies and goods, to transfer, adapt and extract a commercial advantage from new knowledge and also to ensure maximum penetration depth of innovation in public life. Universities as a basis of knowledge genesis system play a crucial role in ensuring of sustained economic growth of any national economy. However, modern entrepreneurial universities can bring benefit to the national economy not only by fundamental academic research and teaching students (Hay, Butt, \& Kirby, 2002). First and foremost, entrepreneurial university is a large institutional subject of regional economy that is acquainted with the specific characteristics of a particular region. If an entrepreneurial university functions properly and its faculty members follow the concept of result-oriented mentality, such university has close and circulating contacts with the various enterprises in a region or even in neighboring regions, with the government, social and educational institutions. Entrepreneurial university acts as a permanent source of project initiatives, involving more and more experts from industry, students, investors and other interested parties in the process of scientific and practical research and innovation developments (Clark, 2001). Dynamic and initiative 
activity of entrepreneurial university containing a large amount of short-term and long-term projects in various fields of knowledge, gradually forms a circle of regular and loyal partners around it. An entrepreneurial University is engaged in research, development, experimental, educational, entrepreneurial and consulting activities. The constant updating and improvement of its own organizational structure and internal business processes, including communication, allow to an entrepreneurial university act as a creator and a examiner of organizational innovation. In addition to that the entrepreneurial university is open to the perception of the successful experience in education and entrepreneurship from the outside and it is constantly developing its internal and external communication channels. In addition to that, an entrepreneurial university is open to the perception of the outside successful experience in education and entrepreneurship and keeps developing its internal and external communication channels.

All of the above properties give to entrepreneurial university a cumulative set of the essential qualities that make it a sustainable institutional, intellectual and organizational core of an innovation-driven cluster in a region. The clustering strategy is justifiably supported by the majority of developed countries as one of the most effective ways to develop economic system. The interaction of enterprises, organizations and institutions within the cluster provides the synergistic effects that can give the significant positive economic impact in development of private businesses and industries and the economy of the region as a whole.

\section{Methods and Materials}

The theoretical basis of the study is the research of Russian and foreign scientists who are interested in analysis of entrepreneurial universities and the creation of industrial clusters based on innovations, and also the author's previous studies in the field of modern higher education development in Russian Federation. The practical foundation of the study is the official materials and data of the Russian research funds, the leading universities in the country, experience of the Russian branch of Triple Helix Association, reviews and reports of the international and domestic rating agencies.

The paper proposes a structural model for the creation of innovation-driven cluster with an entrepreneurial university as an organizational and intellectual core, as well as the author's method of quantitative evaluation of the positive economic impact of such cluster for the regional economy. This method includes an analysis of the most important indicators of the production in the region in the short and long term. In the short term the offered indicators of the effective development of a regional innovation-oriented cluster are the effect of cluster increment, sustained profit growth of enterprise (for 3 years in a row), increase in the share of high technology and innovative goods in the whole structure of production of company, which is included in cluster, and growth of profitability. In the long run, it is possible to estimate the indirect influence of the cluster on the regional economy: changing the region's position in the overall national ranking of subjects of the Russian Federation, positive growth rate in the number of enterprises in the region, increase of the investment flow in the region, as well as the reduction of the budget dependence of the region.

\section{Results}

Today, according to the data of the European Institute of Management (IMD, Lausanne, Switzerland), Russia is in 38th place in the ranking of the current competitiveness of the 60 countries included in the ranking in 2014, below countries such as Poland, Indonesia, Kazakhstan, Chile, Latvia, Lithuania etc. This rating is based on analysis of 333 indicators in 4 main spheres: efficiency of government, economic conditions, infrastructure and business environment. Despite a number of difficulties in the national economy, for several years, the United States have been heading the World Competitiveness Ranking because this country has one of the most developed innovative economies in the world.

Effective export policy, high standards of business management as well as a continuous process of intensive development of innovations help the small economies such as Singapore, Switzerland etc., to remain in the Top-5 of the ranking despite the fact they do not have large reserves of resources (WEF, 2013). For a country with such a scientific and natural resource potential, such as Russia, 38th position can be explained, first of all, by disadvantages of strategic management, errors in the realization of economic policy and misplaced priorities of economic development although there is a positive trend for Russian economy in this ranking (plus 10 seats in the last 2 years) (IMD, 2013). The world economy has no longer relies only on the development of individual enterprises, economic entities of small and medium-sized businesses. More and more developed countries prefer the concept of the management of the aggregated systems, which allows to receive a synergistic effect of the interaction and to support promising, strategically important industries in the form of the creation of industrial clusters. 
Table 1. The World competitiveness ranking (IMD, 2014)

\begin{tabular}{ccccc}
\hline Country & $\begin{array}{c}\text { Position in ranking } \\
\text { 2014 }\end{array}$ & $\begin{array}{c}\text { Position in ranking } \\
2013\end{array}$ & $\begin{array}{c}\text { Change of } \\
\text { position }\end{array}$ & $\begin{array}{c}\text { World Competitiveness } \\
\text { Index in 2014 (\%) }\end{array}$ \\
\hline The USA & 1 & 1 & - & 100.0 \\
Switzerland & 2 & 2 & - & 92.4 \\
Singapore & 3 & 5 & up 2 & 90.9 \\
Hong Kong & 4 & 3 & down 1 & 90.3 \\
Sweden & 5 & 4 & down 1 & 85.8 \\
$\ldots$ & $\ldots$ & $\ldots$ & $\ldots$ & $\ldots$ \\
Latvia & 35 & 41 & up 6 & 61.8 \\
Poland & 36 & 33 & down 3 & 61.7 \\
Indonesia & 37 & 39 & up 2 & 59.5 \\
The Russian & 38 & 42 & up 4 & 57.9 \\
Federation & & & & \\
Spain & 39 & 45 & up 6 & 57.9 \\
$\ldots$ & $\ldots$ & $\ldots$ & $\ldots$ & $\ldots$ \\
Greece & 57 & 54 & down 3 & 42.2 \\
Argentina & 58 & 59 & up 1 & 39.5 \\
Croatia & 59 & 58 & down 1 & 38.9 \\
Venezuela & 60 & 60 & - & 34.2 \\
\hline
\end{tabular}

In 2013, the Government of the Russian Federation adopted The Decree No.188 (Ruzhina, 2014), which governs the rules for the distribution and allocation of grants for the territorial entities of the Russian Federation on the implementation of the strategic development programs for the pilot innovative regional clusters from the federal budget. At the moment the first 13 pilot clusters, specified in the Decree, have already received the state financial support. Another one will receive a financial tranche in 2014. On average, each cluster can expect 100 million Rubles of the state financial assets, which is comparable with the level of support of foreign clusters. The Ministry of Economic Development of the Russian Federation supposes that this big cluster project will be a powerful incentive for the active development of the territories.

In the context of the declared state policy of building an innovative society and its highest form - the knowledge-based economy, the most preferable type of cluster organization is innovation-oriented cluster, because it largely determines the industrial, social and financial structure of the region where it operates. Primarily, this type of cluster is aimed at creating a dynamic group of companies that are using advanced technologies and know-hows in production process. Also such cluster can help to attract talented workforce. The innovation-driven clusters consume and accumulate venture capital, generate a vector of academic research, stimulate the additional vocational training, increase the motivation to the long life learning, and initiate the opening of new research and design organizations and think tanks.

Usually, in developed countries, where experts observe long-term sound functioning of clusters (the United States, France, the Netherlands, Finland etc.), one of the largest participants in the innovation-oriented cluster is a University. However, can it be asserted that most of the Russian universities are ready to take center position in the chain of practical knowledge generation needed by business? Are they aware of the needs of the enterprises and workable channels of knowledge translation and approbation of new findings in the real world? Unfortunately, the practice of some projects, even in matters of collaboration with entrepreneurs regarding to development of competency standards of training, let to us to conclude that the Russian universities are ready, but not all and not always.

The thing is that the focus of attention of the average Russian university, especially regional one, is a classic educational process - the enhancement of a set of competencies of students in strict compliance with the Federal State Educational Standards, that leaves little freedom during the planning of curriculum and working programs. Any change, even in this common sphere for the Russian universities, requires multilevel coordination, consumes much time and resource. Model of the organization of the educational process in the modern higher education (except a small number of federal universities) leaves very little time for classic academic research and almost has no instruments of financial motivation of faculty that would make professors to pursue practice-oriented scientific activity, to realize their projects on the university base, to attract venture investments, to commercialize created innovations and adapt them to the specific needs of a market (Korzhenevskaya \& 
Chigirinskaya, 2012). The personal financial results of teachers and students are usually incomparable with their input efforts (Shakhovskaya \& Korzhenevskaya, 2012). The most part of financial benefit is absorbed by bureaucracy system. The current universities' performance indicators also take into account mostly the level of academic training and professional competence of graduates, the level of employment at the end of higher school. In the regional universities the curriculum has a very low share of such advanced forms of education as training at enterprises, personal coaching, distance learning and dual training. The basics of organizational design, economic modeling, project management are weakly highlighted.

Taking into consideration the situation in Russian higher education, described above, the hypothesis, that the traditional university can really become the foundation of the knowledge-based economy or a productive center of innovation clusters, is hardly probable in nearest future. However, there are some higher institutions which are capable of solving this problem and which are ready to cope with the challenge of developing innovative clusters in Russia - the entrepreneurial universities.

Entrepreneurial university, according to J. Ropke (2000), is a university, showing entrepreneurial behavior, entrepreneurial initiative and entrepreneurial mentality of teachers, administrators and students. It can be identified by evident gradual structural changes and institutional integration of the University into the regional economic environment. It is important to understand that the entrepreneurial university is a kind of a way to organize the operational activities of the University. So it is not directly tied to entrepreneurship as a dominate discipline. Within the concept of the entrepreneurial university, medical, technical, humanitarian, construction and any other university can be organized.

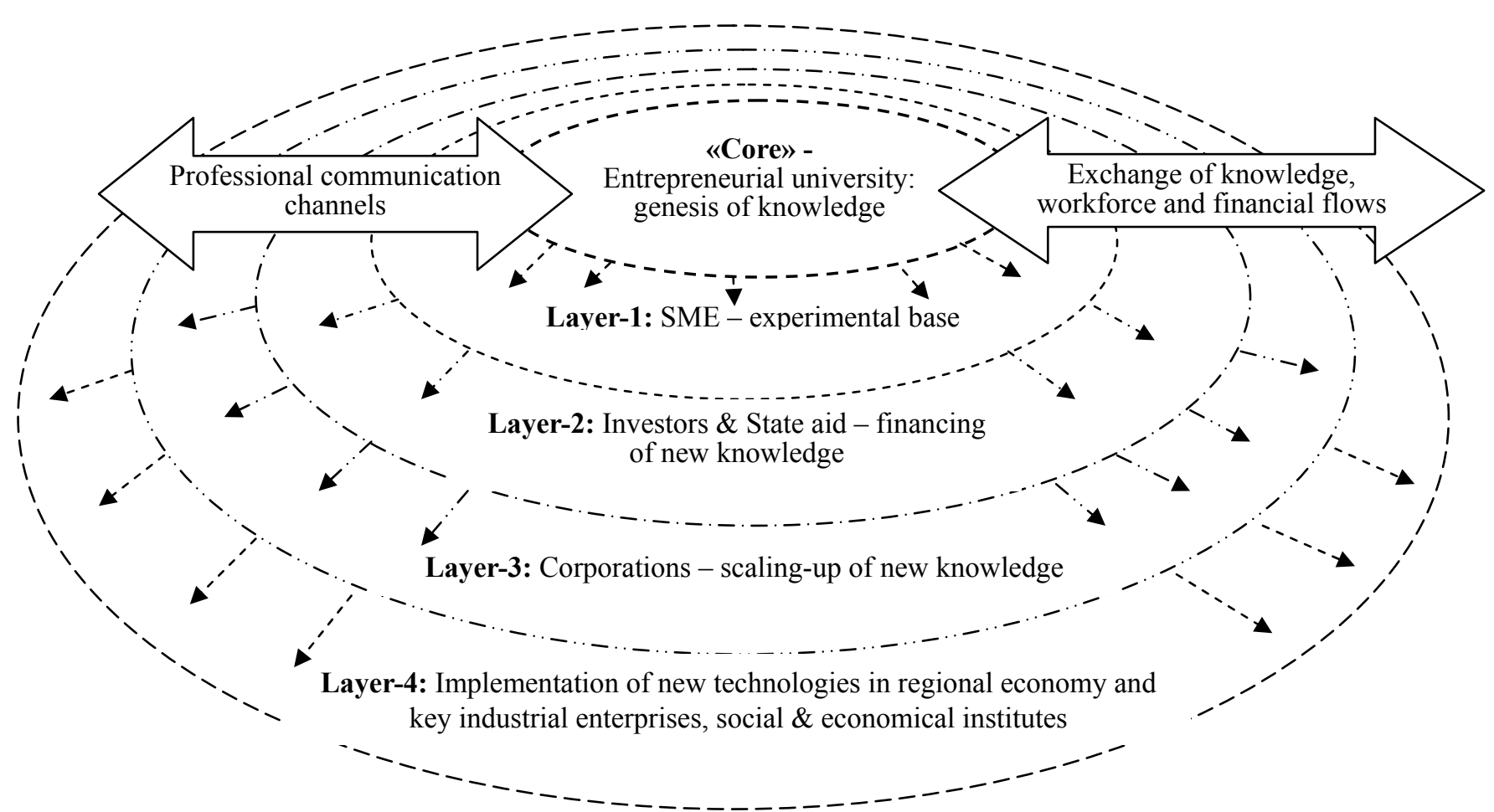

Figure 1. The model of innovation-driven cluster with an entrepreneurial university

In September 2011, the Association of Entrepreneurial Universities in Russia (Association of the Triple Helix in Russia, 2014) was created by the National Research University (NRU) "Moscow Institute of Physics and Technology Institute," NRU "Moscow Institute of Steel and Alloys", St. Petersburg national research university of Information Technologies, Mechanics and Optics, Tomsk State University of Control Systems and Radio Electronics, Skolkovo Foundation and others.

In 2012, the research-to-practice conference "The development of entrepreneurial universities as the backbone elements of innovative regional clusters" was held by the Association of Entrepreneurial Universities of Russia and the Skolkovo Foundation with the support of the Russian Venture Company and Tomsk University of Control Systems and Radio Electronics in Tomsk (Skolkovo Foundation, 2012). This conference became a 
platform for the exchange of expert opinions of the vice-rectors on the strategic development of leading national research universities in Russia, the representatives of the State Corporation "Russian Technologies" and defense-industrial complex "Oboronprom", the managers of the technological platform "Medicine of the Future", the leaders of the developing innovation-driven cluster "Information technology and electronics of the Tomsk region", delegates from the Skolkovo Fund and the Association of innovative Regions of Russia. First time ever in Russia this thematic conference was held in such a large scope. The speakers of the conference focused their attention on the mutual expectations, discussion of tools and mechanisms for mutually beneficial strategic partnership. As it was found out, the Russian innovative regions confer on the entrepreneurial universities primary responsibility for education and formation of the institutes of business environment in which created innovation and actual business competencies will be mastered and reproduced: project management, the combination of the various technologies and scientific spheres in manufacturing process, registry and management of innovative business. Regional authorities make the policy in the field of innovation and put the significance of innovative regional clusters on the central place. They believe that the higher institution can be not only a source of highly qualified personnel and technology for companies-participants of the cluster, but also can present the tools of rapid introduction of technologies into widespread use.

Simplified model of innovation cluster with an entrepreneurial university as a organizational and intellectual core can be represented as follows:

In the model the boundaries between the layers are shown in phantom because, depending on the nature of the generated knowledge, the innovations can be transferred to the receiving point layer by layer through the all layers or can be directly passed to the layer of appointment for which it has the greatest value and where its immediate use is possible.

1. "Core" - an entrepreneurial university. Here the generation and transmission of standards, technologies or innovative goods, test models and samples, knowledge and competitive specialists to the outside takes place. University makes primary formalization, verbalization and algorithmization of the new gained knowledge. Here the created innovation may be partially developed, demonstrated and assigned to the "Layer-1" through the support of small innovative enterprises that run on the basis of the university, the experimental sites and laboratories, meetings with representatives of industry leaders scientific conferences, round tables, briefings with the media and mass communication tools. Depending on the destination for the first time generated knowledge, it should be immediately used in a large scale and actively thrown in to the broad mass of users or, on the contrary, be passed a narrow target audience fast and accurately enough. Thus, already at the stage of consideration of problems related to functioning of the "core" of innovation cluster, it becomes apparent the importance of establishing a strong and professional channels of communication between all the "layers" of the cluster, so that knowledge in any form can be transferred from the place of origin to the point of use without distortion and at the right time. Therefore, the department of public relations with the high qualified and competent experts, capable of organizing the whole process of communication with the university environment of economic and social system, should be organized in a university of entrepreneurial type along with marketing service.

2. "Layer-1". Approbation of new technologies. Usually this layer includes the small and medium-sized enterprises that are more mobile in the decision-making and able to agree and start small-scale production faster, using these new technologies or implementing the new business process models in an enterprise.

3. "Layer-2". State support and investment attraction. Experts on public relations can provide invaluable assistance also in matters of the establishment of public-private partnerships and the organization of productive communication between developers of new knowledge and local authorities (Morozova, Korzhenevskaya, Mysin, 2014). At the moment, because of the dominance of traditional subsidized mechanisms of higher education financing, this direction of activity in universities is undeservedly neglected. This misunderstanding is common for senior management of the universities who does not always understand why the university should build active communication with the external environment and for government of the country which adopt the law confirmed the absence of position of a specialist in public relations in Qualification List of Job Positions of Top Managers, Experts and Employees in higher education in Russia.

4. "Layer-3". The level of technology expansion and launch large-scale production. Usually this layer is represented by large industrial companies and related to them organizations. "Layer-3" is the level of long-term and medium-term contracts, involving the subjects of the "Core", "Layer-1" and "Layer-2". Level of joint strategic planning and making a 'road maps' and diffusion of technology and knowledge to the masses. Within the framework of this stage of clustering and the formation of the "Layer-3" the big significance has another 
category of workers - project managers. All of the entrepreneurial university employees should possess this competence in order for the entrepreneurial university can stay a full participant in the production process, not only generator of new knowledge or connecting channel between science and real economy. A university can carry out the consulting support of projects. That remains its financial interest and gives a new impetus to the improvement of the already approved technology. Moreover, it is desirable that the project teams were created from the leading teachers of the department, experts in specific areas. They will have the opportunity to enrich their lecture by valuable practical examples and to attract students to perform simple tasks within the project they are consulted. It partly reduces the cost of the project for the producer, and also poses a serious motivation for professional development for the students themselves, that, ultimately, makes a positive impact on the achievement of the University in its traditional purpose - the training of highly demanded graduates in the labor market (Shakhovskaya \& Korzhenevskaya, 2012).

5. "Layer-4". Further transfer of the economic effects of the use of knowledge, created in the regional economy, and the transfer of new ideas within the industry or on the scale of the national economy through the exchange of experiences at business forums, trade shows and so on.

The innovation-driven cluster as a kind of interaction between the different structures can be arranged in any industry. Most pronounced effect of clustering may occur in the industry of nanotechnology, information and electronic technologies, as well as agriculture and finance. But even for such sector of the national economy as education the effect of the construction of innovation-oriented cluster with an entrepreneurial university as the core will be very significant. As an example, lets consider the formation of the cluster of education enhancement in the Tomsk region. The "core" of the cluster is the Tomsk State University, a member of the Association of Entrepreneurial Universities of Russia (Project of Tomsk cluster of education enhancement, 2013).

Under the cluster of education enhancement it is considered a special type of cluster, which main task is the production and implementation of new standards, concepts and technologies in the field of education.

The project of the cluster of education enhancement says that the Tomsk region, its $R \& D$, educational and entrepreneurial communities declare the intention of the formation of the zone of advanced development in the field of education, with a further transfer a successful outcome to the whole system of higher education in Russia for the assurance of the third wave of industrialization.

For more than 10 years in Tomsk region the model of innovation development of the territory is progressively implemented. Tomsk universities have traditionally been a town-forming organizations and the leaders of Russian higher education. Four Tomsk universities (Tomsk State University, Tomsk Polytechnic University, Siberian State Medical University and Tomsk State University of Control Systems and Radio electronics) have won the open tender for selection of programs for the development of innovation infrastructure, including support of small innovative enterprises and the federal educational institutions of higher education. These universities have signed an agreement on inter-university cooperation in the sphere of formation of innovation infrastructure. According to this agreement, the students, the professors and researchers now have access to the resources of innovative infrastructure and they can create joint multidisciplinary projects. Over the last 5 years the total amount of the regional budget for the formation and development of regional innovation system has increased in 4.5 times. In 2010 it already exceeded 1.4 billion rubles, and with the support of federal and private investment - 10 billion rubles (Project of Tomsk cluster of education enhancement, 2013).

In Tomsk almost all of the elements of innovation infrastructure has already created, but still it is difficult to make a qualitative breakthrough in the technological system and the design of the education system to meet modern challenges of mobility, convergence and multidisciplinarity, to provide an access to world export markets for education. Formation of stable connections within the cluster, update the existing business processes and designing the missing institutional elements of the cluster will provide an opportunity to significantly increase the capitalization of the region.

The educational system, projected in Tomsk cluster, is aimed at creating new knowledge and skills throughout human life that gives a person the opportunity to think, act and engage in creative work in an increasingly complex world in any period of gradually increasing longevity.

The predicted effects of clustering in the Tomsk region are: accumulation of resources in the region, attracting necessary resources, the organization of full-cycle production and implementation of new ideas in the priority sectors of the economy; decline in the share of transaction costs in the value chain and additional competencies; cooperation in respect of raw materials and sales - for a cluster of education enhancement it is the recognition of the merits and prestige not separate educational institutions of the city, but a general idea of the highest educational standards of the entire city of Tomsk by population; removing structural barriers of innovation 
production; common infrastructure policy; reduction of entry barriers for the certain business that improves the competitive position of cluster members and the entire cluster as a whole; synergistic and nonlinear effects; organization and agreement of new, previously disparate, competencies and the creation of new professions and jobs etc.

\section{Discussion}

Of course, there are some difficulties in the organization of clusters of the education with an entrepreneurial university as a core. Foremost the Russian managers prevent lack of knowledge and inability to apply the global developments in the local conditions (Uvarov \& Perevodchikov, 2012). It is also evident that there is a lack of overall trust in today's Russian business culture, but it is essential for the cooperation establishment, joint growth and building a cluster. The institution of credibility has a huge influence on speed and effectiveness of organizational and management decisions.

Another difficulty with which ought to face is the need for re-engineering of the university itself (Mora \& Villarreal, 2001), when creating an innovation-oriented cluster headed by entrepreneurial university, and such deep transformations often come into a conflict with a long tradition and the prevailing culture of the university.

The economic effect of the creation of innovation-oriented cluster for the regional economy can be estimated both in the short and in the long run.

In the short run the economic effect of clustering can be estimated according to four major factors:

1) the effect of the cluster's increment (ECI);

2) sustainable growth of the company's profit (for 3 consecutive years);

3) the share of high-end technologies and innovative products in the overall structure of the company, which is a part of the cluster;

4) growth of production's profitability.

The effect of a cluster increment $\mathrm{E}_{\mathrm{c}}$ in physical terms can be calculated as the increment in output produced by the organizations of the cluster, as compared to the overall increment in output in the region. In order to quantify the importance of this effect, we introduce some notation.

Assume that the total number of companies are registered in the region equal to $n+m$. Of these, $n$ companies are included in the innovation cluster, and $m$ enterprises are out of it. The current evaluation period (year) is denoted by $t$, the previous period is denoted by $t-1$. Let $V_{c}$ be the volume of all enterprises in the cluster, $V_{c i}$ - the volume of the $i$-th enterprise in the cluster. Then,

$$
V_{c}=\sum_{i=1}^{n} V_{c i}
$$

Let $V_{b}$ be the volume production of all the enterprises that are not members of the cluster, and $V_{b j}-$ the output of the $j$-th enterprise not included in the cluster. Then,

$$
V_{b}=\sum_{j=1}^{m} V_{b j}
$$

Then the total output in the region $V_{R}$ can be calculated by the formula:

$$
V_{R}=\sum_{i=1}^{n} V_{c i}+\sum_{j=1}^{m} V_{b j}
$$

The total increment in output in the region for one year $\Delta V_{R}$ is calculated as:

$$
\Delta V_{R}=\left(\sum_{i=1}^{n} V_{c i}+\sum_{j=1}^{m} V_{b j}\right)_{t}-\left(\sum_{i=1}^{n} V_{c i}+\sum_{j=1}^{m} V_{b j}\right)_{t-1}
$$

Given that,

$$
\Delta V_{c}=\left(\sum_{i=1}^{n} V_{c i}\right)_{t}-\left(\sum_{i=1}^{n} V_{c i}\right)_{t-1}
$$

The effect of cluster increment in physical terms can be calculated by the formula: 


$$
E_{c}=\frac{\Delta V_{c}}{\Delta V_{R}}=\frac{\left(\sum_{i=1}^{n} V_{c i}\right)_{t}-\left(\sum_{i=1}^{n} V_{c i}\right)_{t-1}}{\left(\sum_{i=1}^{n} V_{c i}+\sum_{j=1}^{m} V_{b j}\right)_{t}-\left(\sum_{i=1}^{n} V_{c i}+\sum_{j=1}^{m} V_{b j}\right)_{t-1}}
$$

In monetary terms, the place of the volume of production in the formula of an effect cluster increment takes an income of the company $I$ (wherein $P$ is the price of the company's products):

$$
E_{c}=\frac{\Delta I_{c}}{\Delta I_{R}}=\frac{\left(\sum_{i=1}^{n} V_{c i} \times P_{c i}\right)_{t}-\left(\sum_{i=1}^{n} V_{c i} \times P_{c i}\right)_{t-1}}{\left(\sum_{i=1}^{n} V_{c i} \times P_{c i}+\sum_{j=1}^{m} V_{b j} \times P_{b j}\right)-\left(\sum_{i=1}^{n} V_{c i} \times P_{c i}+\sum_{j=1}^{m} V_{b j} \times P_{b j}\right)_{t-1}}
$$

The range of the ECI optimal values lies in the interval from 0 to 1 . The closer the value of $E_{c}$ to 1 , the higher an effect of the company's activity within the cluster established in the region.

Another indicator by which can be estimated the positive economic effect of creating a regional innovation-oriented cluster is a steady growth in profits of the enterprise, which is a part of the cluster for at least 3 consecutive years. The most important condition for the estimation of the indicator is its stability. Despite the possible deviations of the absolute values, the company's profit growth that is in the cluster have to be a positive value, despite some market fluctuations.

The work of the enterprise within the cluster will provide this indicator smaller fluctuations than that of firms outside the cluster operating in less favorable institutional environment.

Over time another parameter characterizing the activities of the innovation-oriented cluster's company, should be changed, that is the share of high technology and innovative products in the total structure of the enterprise should be increased.

Let $V_{\text {innov }}$ - be the volume of high-end technology and innovative products, manufactured by the enterprise of the cluster, $V_{\text {total }}-$ is the total volume produced by the enterprise. Then the presence of the positive economic effect from the establishment of a regional innovation-oriented cluster will be observed under the condition:

$$
\Delta V_{\text {innov }}=\left(\frac{V_{\text {innov }}}{V_{\text {total }}}\right)_{t}-\left(\frac{V_{\text {innov }}}{V_{\text {total }}}\right)_{t-1}>0
$$

The positive effect of clustering should be ideally manifested also in increasing the profitability of production. This indicator is calculated as the ratio of the net profit margin to the sum of its capital stock and normalized current assets. For the company of the innovation-oriented cluster this figure should be higher than the industry average, calculated annually on the basis of public statistics.

In the long run positive effects of clustering should be viewed not only at the level of individual companies, but also at the level of the region's economy. It is manifested primarily in:

1) change of the region's position in the national ranking of the socio-economic situation of the Russian Federation, which is compiled by the rating agency RIA News based on official statistics and takes into account indicators of the scale and efficiency of the economy, fiscal and social spheres;

2) the positive dynamics of the number of enterprises in the region, which manifest as the positive difference between the number of the registered companies for the year and the number of the companies closed down at the same period;

3) the increase flow of investments in the region;

4) reducing the region's dependence on financial subsidies and other aid budgets of different levels.

Besides the economic benefits, the existence of a major innovation-oriented cluster with an entrepreneurial university as an intellectual and organizational core can bring significant social benefits in a region. As the entrepreneurial university is an educational institution first of all, so there should be formed ethical standards and benchmarks of business communications. The entrepreneurial university with the active assistance of the other cluster members provides the regional economy with the well-trained staff, adapted to work in the specific conditions of their area (Gibb \& Hannon, 2006). 
However, the young professionals even in the process of learning are actively involved in the production and communication environment of the region, have an access to the programs and practices of training, can find suitable jobs and begin to develop as professional practitioners. All of it increases the loyalty of young professionals to their region and reduces the outflow of intellectual resources of the region.

\section{Conclusion}

The process of cluster creating is associated with a high concentration of the entrepreneurial initiative in a particular industry and other related fields. The level of this initiative is largely determined by the rule of law and political climate in the country, the level of the business rights protection in the high risk area. Therefore, one of the key objectives of the cluster development should be relevant and systematic policy to improve the business (investment) climate. Regardless of the prevailing scientific concepts, the reality always modifies the final result of the efforts made by a person or a group. Indeed, nowadays it is impossible to create a new valid and actively developing innovative cluster without cooperation of the Russian business and science.

Many long-living clusters in the Russian economy work largely due to lobbying the interests of the industrialists in administrative sidelines. But emphasis just only on personal relationships and authority of the heads of the enterprises strongly reduces the ordinary employees' motivation to create innovations at the enterprises that cluster comprises. It is leading to a gradual backlog of the Russian economy from a group of the most advanced countries. The concept of entrepreneurial universities as the centers of innovation-driven clusters will allow not only to return the Russian science into the real production chain, but also to improve significantly the quality of higher education in the country.

\section{References}

Association of Triple Helix in Russia. (2014). Retrieved June 5, 2014, from http://triplehelixassociation.ru/

Clark, B. (2001). The Entrepreneurial University: New foundations for collegiality, autonomy, and achievement. Higher Education Management, 13(3), 9-25

Gibb, A., \& Hannon, P. (2006). Towards the entrepreneurial university? National Council for Graduate Entrepreneurship, Working Paper 035/2006. Retrieved April 29, 2014, from http://ncge.com/files/biblio 742.pdf

Hay, D. B., Butt, F., \& Kirby, D. A. (2002). Academics as Entrepreneurs in a UK University. In G. Williams (Ed.), The Enterprising University. Reform, Excellence and Equity (pp. 132-141). Buckingham: SRHE \& Open University Press.

IMD. (2014). World Competitiveness Yearbook Ranking. Retrieved June 6, 2014, from http://www.imd.org/ news/2014-World-Competitiveness.cfm

Korzhenevskaya, O. N., \& Chigirinskaya, N. V. (2012). Business role in business education modernization in Russia, problems and prospects. International scientific periodical "Modern fundamental and applied researches", 2, 158-162.

Mora, J., \& Villarreal, E. (2001). Breaking Down Structural Barriers to Innovation in Traditional Universities. Higher Education Management, 13(3), 57-66

Morozova, I. A., Korzhenevskaya, O. N., \& Mysin, M. N. (2014). The mechanisms of private public partnership as commercialization potential of educational services. Review of Volgograd State Technical University. Series "Actual problems of reform of the Russian economy (theory, practice, perspectives)", 18(4-13), 61-66

Project of Tomsk cluster of education enhancement. (2013). Retrieved May 2, 2014, from http://cluster.arch ipelag.ru/conc.html\#1

Ropke, J. (2000). The Entrepreneurial University: Innovation, academic knowledge creation and regional development in a globalized economy. Retrieved June 5, 2014, from http://etc.online.uni-marburg.de/ etc $1 / 010 . p d f$

Ruzhina, O. (2014). The cluster incentive. Strategy, 4(14). Retrieved July 1, 2014, from http://strategyjournal.ru/ $\mathrm{ru} /$ klasternyy-stimul-0

Shakhovskaya, L. S., \& Korzhenevskaya, O. N. (2012). The motivation of youth for the professional competence achievements as a condition of knowledge-based economy development (pp. 151-158). Proceedings of the all-Russian youth scientific and practice conference, Oct. 7-8, 2012 г. Innovation potential of youth in the development of Russia, Ekaterinburg, Russia. 
Skolkovo Foundation. (2012). Retrieved May 14, 2014, from http://community.sk.ru/events/1339.aspx

Uvarov, A., \& Perevodchikov, E. (2012). The Entrepreneurial University in Russia: From Idea to Reality. Procedia - Social and Behavioral Sciences, 52, 45-51.

World Economic Forum. (2013). Schwab, K. The Global Competitiveness report 2012-2013. Retrieved May 20, 2014, from http://www3.weforum.org/docs/WEF_GlobalCompetitivenessReport_2012-13.pdf

\section{Copyrights}

Copyright for this article is retained by the author(s), with first publication rights granted to the journal.

This is an open-access article distributed under the terms and conditions of the Creative Commons Attribution license (http://creativecommons.org/licenses/by/3.0/). 